\title{
Relationships between soil characteristics, topography and plant diversity in a heterogeneous deciduous broad-leaved forest near Beijing, China
}

\author{
B.J. Fu ${ }^{1,3}$, S.L. Liu ${ }^{1,2}$, K.M. Ma ${ }^{1} \&$ Y.G. Zhu ${ }^{1}$ \\ ${ }^{1}$ Key Lab of Systems Ecology, Research Center for Eco-Environmental Sciences, Chinese Academy of Sciences, \\ P.O.BOX 2871, Beijing 100085, China. ${ }^{2}$ Institute of Environmental Science, Beijing Normal University, Beijing \\ 100875, China. ${ }^{3}$ Corresponding author ${ }^{*}$
}

Received 26 November 2002. Accepted in revised form 4 September 2003

Key words: multivariate statistical analysis, plant diversity, soil properties, topography

\begin{abstract}
Patterns of biodiversity affect soil properties at different scales, conversely, soil characteristics and landscape features influence biodiversity. It is important to determine these relationships for understanding ecosystem processes. Many studies have carried out during the last few years mainly concentrated on factors that influence plant diversity in grassland or shrubland. Focused on the topography and forest heterogeneity for a warm temperate-zone deciduous broad-leaved forest in the Donglingshan Mountains near Beijing, detailed plant diversity, topography and soil features of 76 plots were investigated in a small watershed. To discern the complex relationships, multivariate statistical analysis techniques (Principal Component Analysis (PCA), Cluster Analysis (CA) and Canonical Correlation Analysis (CCA)) were employed. The results of PCA and CA showed that soil organic matter (SOM) is an important indicator to soil fertility. The coverage, richness and $\alpha$-diversity index of three layers of plants (tree, shrub and herb) have unique features under different soil fertilities. High fertility plots often exist on south-facing slopes, in upper slope positions, and have gentle slope gradients. The coverage, richness and $\alpha$-diversity index (Shannon index) of tree and shrub layers are the highest in mid-fertility plots, which have the highest available phosphorus (AP) and potassium (AK) contents, but those same summary descriptors for herbs are the least. CCA analysis elucidated the relationships of three different index groups (topography, soil and plant). Elevation and aspect have a close relationship with shrub richness and $\alpha$-diversity. Elevation is also an important factor influencing SOM. SOM and total nitrogen have the greatest effect on plant characteristics (mainly shrub coverage) among all soil factors.
\end{abstract}

\section{Introduction}

Variations in plant types and landscape features can influence many natural phenomena and ecological processes, including soil nutrient and water interactions (Fu et al., 2000). Variation in soil resource levels is common and is important to plants. At relatively large spatial scales, the resources available to plants change as the soil type changes, and this variation has wellknown effects on the distribution of plant species. At smaller spatial scales, soil resources continue to show considerable spatial heterogeneity, often down to the

*FAX No: +86-10-62943840. E-mail: bfu@mail.rcees.ac.cn smallest scale at which measurements are taken (Jackson and Caldwell, 1993). Small-scale heterogeneity can have a large impact on the performance of individual plants (Miller et al., 1995), and hence, on the structure and dynamics of plant populations and communities.

Although Watt (1947) recognized how vegetation pattern as well as biotic interactions in neighboring patches can affect microclimate and soil factors, only relatively few contemporary researchers have extended the work on investigating their relationships. There is evidence that pattern influences the spread of disturbance, the movement and persistence of organisms, and the redistribution of organic matter and 
nutrients (Pickett and Cadenasso, 1995). Especially in semi-arid terrestrial ecosystems, patchiness may play a critical role in maintaining ecosystem productivity by concentrating limited resources (Ludwig and Tongway, 1995; Aguiar and Sala, 1999).

Plant communities and soil conditions are influenced by landscape features, including topography, landscape position, slope gradient and elevation. Previous research, however, has mainly focused on the relationships between soil and plants or plants and topography. Also, few studies have evaluated the relative importance of individual factors. The interrelationships between them need further studies (An et al., 1997; Liu et al., 1996). Regression and geostatistic analysis for studies of relationships between soil factors and other environmental factors may not be suitable when large numbers of variables are involved (Zhang and Oxley, 1994) and instead other recommended methods have been used in recent studies. Intrinsic methods such as principal component analysis (PCA) and extrinsic methods such as linear canonical correlation analysis (COR) and canonical correlation analysis (CCA) have been applied to soil studies (McBratney and Webster, 1981; Odeh et al., 1991). Different methods should be integrated for comprehensive analysis and we accomplish that in this paper.

Studies have focused on controls over spatial variability in soil properties and processes at local scales (less than $2 \mathrm{~km}$ ). Literature from the 1980 s on grassland biogeochemistry shows strong spatial variability at landscape scales, induced by topographic variation (Schimel et al., 1985a, b; Aguilar and Heil, 1988; Yonker et al., 1988). Recent work has indicated that total soil organic matter and nutrient turnover are strongly influenced by spatial patterns in plant species composition (for example, Wedin and Tilman, 1996; Vinton and Burke, 1995, 1997). No further research has focused on forest ecosystems.

The warm temperate deciduous broad-leaved forest zone was heterogeneous due to natural succession in Donglingshan Mountain region, Beijing, China, but it is still an important area for research owing to its rich biological diversity and diverse topography (Chen et al., 1997). The general objectives of this study were to investigate the quantitative relationships between plant diversity, topographical features and soil properties and to assess the relative importance of topography and plant diversity in controlling spatial variability in soil nutrients by using a regression and correlation perspective.

\section{Methods}

Study area

Donglingshan Mountain is an extension of Xiaowutaishan Mountains and belongs to the broader Taihangshan Mountains, $100 \mathrm{~km}$ northwest from Beijing City, China. The study area, the Beijing Forest Ecosystem Research Station of the Chinese Academy of Sciences, is located at $40^{\circ} 00^{\prime}-40^{\circ} 03^{\prime} \mathrm{N}$ and $115^{\circ} 26^{\prime}-115^{\circ} 30^{\prime} \mathrm{E}$. The area has been much influenced by erosion. Soil type is brown soil classified as Eutric cambisol (FAOUNESCO, 1988). The area has a typical warm temperate continental monsoon climate with average annual precipitation of 500-650 mm. The mean annual temperature is $5-10{ }^{\circ} \mathrm{C}$. The vegetation, a broad leaf forest, has been seriously degraded, and at present the main vegetation types are secondary and artificial forests. The altitude of most of the area is more than $1000 \mathrm{~m}$ above sea level with an amplitude of relief of 300-400 m (Ma et al., 2000).

The zonal vegetation of the Donglingshan Mountain region is highly heterogeneous warm temperatezone deciduous broad-leaved forest (Chen, 1997), including mainly oaks (Quercus spp.), mixed species (e.g., Tilia spp., Ulmus spp., Acer spp., Juglans mandshurica and Fraxinus rhynchophylla etc.), birches (Betula spp.) and poplar (Populus davidiana). There also are some conifers and some shrubs (e.g., Prunus spp., Vitex negundo var. hetertophylla, etc.)(Ma et al., 2000).

\section{Vegetation investigation and soil sampling methods}

The vegetation of 76 sites was investigated in midsummer 2001. At each site a homogeneous plot of $400 \mathrm{~m}^{2}(20 \times 20 \mathrm{~m})$ was chosen to produce a detailed inventory of the forest. Within each plot, three quadrats $(5 \times 5 \mathrm{~m})$ on the diagonal line were chosen for investigation of shrub vegetation, and internal $(1 \times 1 \mathrm{~m})$ quadrats were used for detailed inventory of herbaceous vegetation.

In the plots, all the individual trees were identified and measured for breast-height diameter, layer coverage, stem height (height of the first major branch) and total height. In the three quadrats, shrubs were identified and measured for diameter, layer coverage and total height, while herbs were identified for layer coverage and height.

Environmental variables such as altitude, landscape position and aspect were recorded for each plot. 
Soil samples were obtained using cores $(5 \mathrm{~cm}$ diameter) from three soil profiles at each site. The soil was sampled at a depth of about $0-30 \mathrm{~cm}$. The three replicate samples were homogenized by hand mixing and large live plant material (roots and shoots) and pebbles in each sample were separated by hand and discarded. The soil samples were air-dried and sieved for determination of soil nutrients. The soil nutrients examined for the surface layer included soil organic matter (SOM), total nitrogen $(\mathrm{TN})$, available potassium (AK) and available phosphorus (AP).

The determination of TN was by the semimicro Kjeldahl method. SOM was determined by the $\mathrm{K}_{2} \mathrm{Cr}_{2} \mathrm{O}_{7}$ titration method after digestion (Nelson and Sommers, 1975). AP and AK were extracted with $3 \%$ $\left(\mathrm{NH}_{4}\right)_{2} \mathrm{CO}_{3}$ solution. After filtering, the filtrate was measured by ICP-AES (Editorial Committee, 1996). Soil $\mathrm{pH}$ was determined in a 1:5 soil-water slurry, using a combination glass electrode (Editorial Committee, 1996). Soil volumetric water contents (SW) were measured by portable time domain reflectometry (TDR) for six times at each site and then averaged.

\section{Statistical analysis}

A data matrix $X(20,76)$ representing 20 indexes of soil, plant characteristics and environmental factors and 76 plots was derived for data processing (Zhang and Oxley, 1994). Environmental factors included aspect (ASP), slope position (POS), slope gradient (GRAD), elevation (ELE). Soil fertility indicators were SW, pH, SOM, TN, AP and AK. Plant diversity was expressed in coverage percentage of trees (COVt), shrubs (COVs) and herbs (COVh), richness of trees (RICHt), shrubs (RICHs) and herbs (RICHh), and $\alpha$-diversity index (Shannon-Winner index) of tree (DIVt), shrubs (DIVs), herbs (DIVh) and all plants (DIV).

The data were coded before processing (Qiu and Zhang, 2000). Aspect was classified into 4 categories: 0.3 represents south, 0.5 southwest and southeast, 0.8 northeast and northwest, 1 north. Slope position was coded into 3 types: 0.4 represented top slope, 1 middle slope, 0.8 bottom slope (Yuan et al., 1988; Zhao et al., 1988; Liu et al., 1996). To unify the different dimensions and remove overlapping information, the data were standardized $[0,1]$ using the following formulae:

$$
x_{i j}^{\prime}=\frac{x_{i j}-\overline{x_{j}}}{S_{j}}
$$

$$
\lambda_{i j}=\frac{x_{i j}^{\prime}-x_{j \min }^{\prime}}{x_{j \max }^{\prime}-x_{j \min }^{\prime}},
$$

where $x_{i j}$ is the $j$ factor of $i$ plot in the raw matrix, $\lambda_{i j}$ is the element of the standardized matrix, $\overline{x_{j}}$ and $S_{j}$ are the average value and standard deviation of the $j$ factor of all plots. $x_{j \text { max }}^{\prime}$ and $x_{j \text { min }}^{\prime}$ represent the maximum and minimum values of the standardized factor $j$.

To investigate complex relationships, multivariate statistical analysis techniques (Principal Component Analysis (PCA), Cluster Analysis (CA) and Canonical Correlation Analysis (CCA)) were used.

PCA was conducted to compute the eigenvalues, and cumulative variance percentage of the standardized matrix $X^{\prime}(20,76)$ using SPSS (Su et al., 2000). Based on the component capacity coefficient values of PCA, representative factors of different groups were selected for CA using Ward's cluster method ( $\mathrm{Su}$ et al., 2000). This method determines the minimum differences within groups but maximum differences between groups. The CCA method was used to illustrate the interrelationships between topography, soil and plant groups. For the latter, three $\mathrm{P} \times \mathrm{N}$ data matrixes were required, respectively, all having the same value of $\mathrm{N}$ (number of plots, $\mathrm{N}$ ). PCA, CA and other analyses were conducted using the SPSS (Su et al., 2000). CCA was conducted using SAS software (Hong and Hou, 2001). Values reported in the text are means followed by standard errors.

\section{Results and discussion}

Topography and plant features classified by soil fertility levels by using PCA and CA

PCA and its interpretation. PCA screened out six components, and their percentage variance values were $25.0 \%, 17.9 \%, 9.2 \%, 7.2 \%, 6.8 \%$ and $5.3 \%$. The components cumulative percentage reached $71.4 \%$ (Figure 1). The radar plots of the six component's coefficients are shown in Figure 1.

The results showed that DIVt (0.89), RICHt (0.87), and DIV (0.84) accounted for most of the first component and SOM (0.91), TN (0.81) and AP (0.76) for the second component. The largest coefficients of the third component were GRAD (0.63), POS (0.54) and ELE (0.47). The first, second and third components represent plant, soil, and topography factors, respectively. The coefficient values illustrate the degree of influence of each factor. The values showed that the 
Table 1. Features soil variables, topographical and plant diversity of three vegetation groups

\begin{tabular}{|c|c|c|c|c|c|}
\hline \multicolumn{2}{|c|}{ Soil, topographical and plant factors } & \multirow{2}{*}{$\begin{array}{c}\begin{array}{c}\text { Group I } \\
\left(\mathrm{N}^{\mathrm{a}}=30\right)\end{array} \\
48.59 \pm 8.64\end{array}$} & \multirow{2}{*}{$\begin{array}{c}\begin{array}{c}\text { Group II } \\
(\mathrm{N}=26)\end{array} \\
70.12 \pm 13.42\end{array}$} & \multirow{2}{*}{$\begin{array}{c}\text { Group III } \\
(\mathrm{N}=20)\end{array}$} & \multirow{2}{*}{$\begin{array}{c}F \text { value } \\
14.92^{* *}\end{array}$} \\
\hline Soil organic matter $(\mathrm{g} / \mathrm{kg})$ & & & & & \\
\hline Total nitrogen $(\mathrm{g} / \mathrm{kg})$ & & $2.39 \pm 0.27$ & $3.24 \pm 0.33$ & $3.29 \pm 0.38$ & $16.72^{* *}$ \\
\hline Available phosphorus (ppm) & & $9.85 \pm 1.27$ & $13.33 \pm 3.06$ & $12.56 \pm 2.48$ & $4.27^{* *}$ \\
\hline Available potassium (ppm) & & $246.76 \pm 37.40$ & $318.48 \pm 54.95$ & $290.76 \pm 46.76$ & $4.25^{*}$ \\
\hline Soil water contents $(\%)$ & & $15.49 \pm 2.26$ & $18.12 \pm 1.76$ & $16.46 \pm 2.40$ & $2.65^{*}$ \\
\hline $\mathrm{pH}$ value $(5: 1)$ & & $6.44 \pm 0.13$ & $6.51 \pm 0.13$ & $6.53 \pm 0.11$ & 0.76 \\
\hline Elevation (m) & & $1348.8 \pm 26.3$ & $1375.0 \pm 37.8$ & $1463.4 \pm 22.4$ & $22.94^{* *}$ \\
\hline Gradient $\left(^{\circ}\right)$ & & $33.9 \pm 3.1$ & $32.3 \pm 2.4$ & $31.7 \pm 1.3$ & $2.38^{*}$ \\
\hline Position & Top slope & 12 & 1 & 19 & $37.31^{* *}$ \\
\hline \multirow[t]{2}{*}{$(\mathrm{N})$} & Middle slope & 9 & 16 & 0 & \\
\hline & Bottom slope & 9 & 9 & 1 & \\
\hline Aspect & South & 7 & 9 & 8 & $3.52^{*}$ \\
\hline \multirow[t]{5}{*}{$(\mathrm{N})$} & Southwest & 9 & 15 & 8 & \\
\hline & \&Southeast & & & & \\
\hline & Northeast & 14 & 1 & 3 & \\
\hline & \&Northwest & & & & \\
\hline & North & 0 & 1 & 1 & \\
\hline Coverage & Tree & $50.17 \pm 7.97$ & $62.50 \pm 4.20$ & $58.75 \pm 8.35$ & $5.66^{* *}$ \\
\hline \multirow[t]{2}{*}{$(\%)$} & Shrub & $64.43 \pm 13.08$ & $78.50 \pm 11.55$ & $58.65 \pm 15.00$ & $3.62 *$ \\
\hline & Herb & $46.03 \pm 14.67$ & $21.77 \pm 9.07$ & $43.80 \pm 13.40$ & $7.32^{* *}$ \\
\hline \multirow[t]{3}{*}{ Species richness } & Tree & $4.80 \pm 0.67$ & $7.31 \pm 0.94$ & $3.95 \pm 0.92$ & $26.20^{* *}$ \\
\hline & Shrub & $10.17 \pm 0.94$ & $13.50 \pm 1.69$ & $9.30 \pm 1.11$ & $18.19^{* *}$ \\
\hline & Herb & $17.80 \pm 1.90$ & $17.42 \pm 1.68$ & $17.75 \pm 1.57$ & 0.09 \\
\hline$\alpha$-index & Tree & $0.49 \pm 0.06$ & $0.68 \pm 0.05$ & $0.41 \pm 0.10$ & $24.19^{* *}$ \\
\hline \multirow[t]{3}{*}{ (Shannon index) } & Shrub & $0.66 \pm 0.07$ & $0.83 \pm 0.09$ & $0.67 \pm 0.09$ & $9.11^{* *}$ \\
\hline & Herb & $0.95 \pm 0.08$ & $0.80 \pm 0.06$ & $0.84 \pm 0.13$ & $2.43^{*}$ \\
\hline & Sum & $2.10 \pm 0.13$ & $2.30 \pm 0.10$ & $1.92 \pm 0.20$ & $21.15^{* *}$ \\
\hline
\end{tabular}

${ }^{*}$ Significant at the $5 \%$ level of probability, ${ }^{* *}$ Significant at the $1 \%$ level of probability;

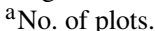

tree $\alpha$-diversity was a key factor in the heterogeneous forest. SOM contents could reflect soil fertility, and slope degree has the greatest impact on other factors. Thus soil, topography and plant factors should be considered in studying the factors influencing forest heterogeneity.

Interpretation of $C A$ and general features of soil, plants and topography. By comprehensive evaluation of the factors and the values of PCA score coefficients, the following representative factors were selected for a cluster analysis: ELE, POS, GRAD, COVt, RICHt, RICHs, DIVt, DIV, SOM, TN and AP. The $11 \times 76$ matrix was clustered using Ward's method. The 76 plots could be divided into three groups at the rescaled distance of 15 . The plot sequence numbers for the three groups are listed in Figure 2. Table 1 shows the means and standard deviations of soil properties, topographical features and vegetation indicators of the different groups.

Three fertility levels can be distinguished based on SOM contents (Table 1). Soil fertility and nutrient availability are closely connected to SOM content and its mineralization. The extent of $\mathrm{C}$ mineralization determines soil nutrient release and therefore nutrient availability. In the study area, soil properties showed high heterogeneity between the plots. Table 1 shows that group II had higher water, AP and AK contents. The average SOM content of group III is 1.71 times that of group I and $\mathrm{TN}$ is 1.38 times. Topo- 

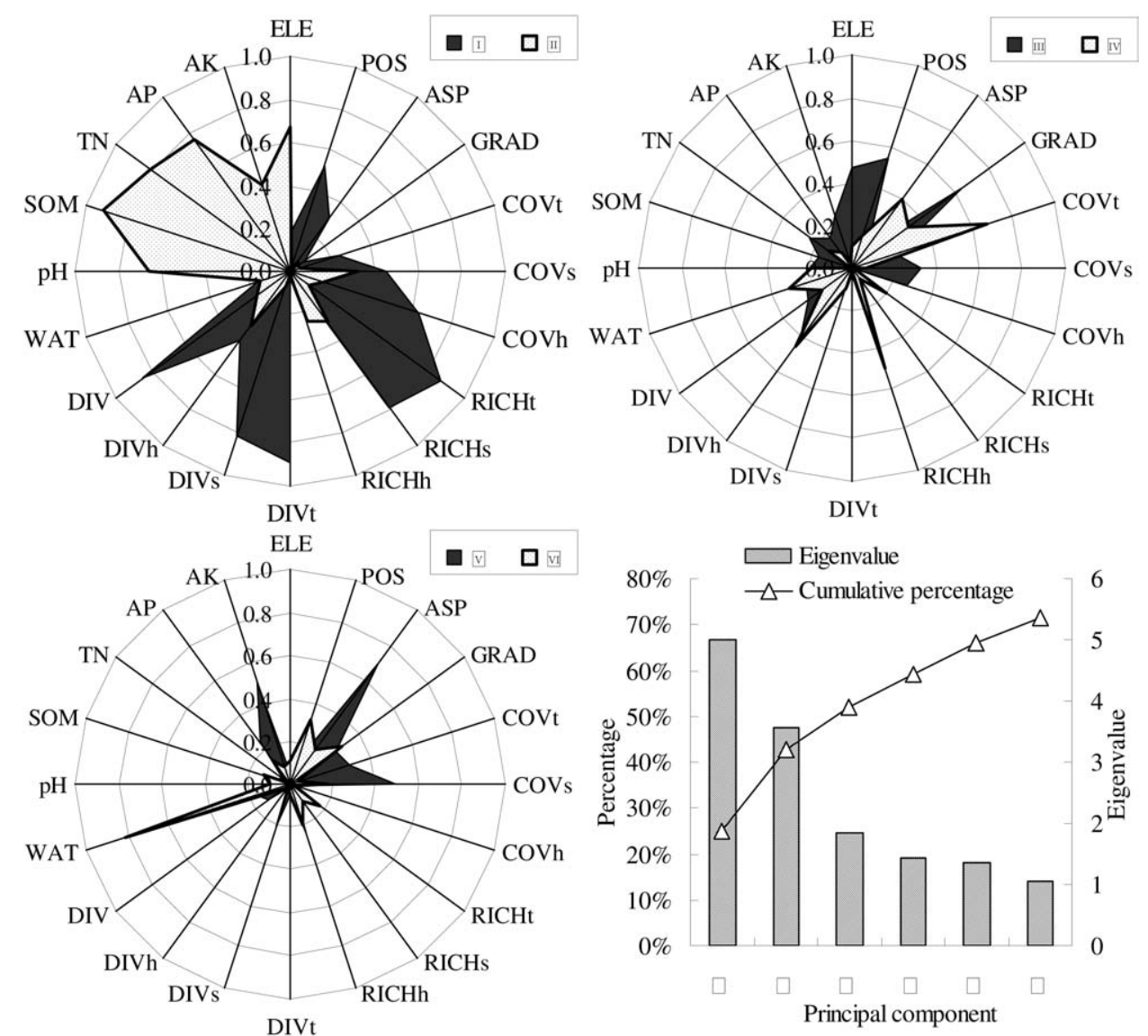

Figure 1. The first six component's capacity score coefficients, their cumulative percentage, and eigenvalues $\left({ }^{*} \mathrm{ELE}=\mathrm{elevation}, \mathrm{POS}=\mathrm{slope}\right.$ position, $\mathrm{ASP}=$ slope aspect, $\mathrm{GRAD}=$ slope gradient; $\mathrm{SW}=$ water contents, $\mathrm{pH}=$ soil $\mathrm{pH}$ value, $\mathrm{SOM}=$ soil organic matter, $\mathrm{TN}=$ total nitrogen, $\mathrm{AP}=$ available phosphorus, $\mathrm{AK}=$ available potassium; $\mathrm{COVt}, \mathrm{COVs}$ and $\mathrm{COVh}$ represent coverage percentage of trees, shrubs, and herbs; RICHt, RICHs and RICHh represent richness of tree, shrubs, and herbs; DIVt, DIVs, DIVh and DIV represent $\alpha$-diversity index (Shannon index) of tree, shrubs, herbs, and all plants).

graphical features for the areas with three soil fertility levels indicated that high fertility often existed on the gentle, upper and south-facing slopes (Table 1). Aspect influences solar irradiation and evapotranspiration, therefore, it also in partly contributed to different soil fertility and plant characteristics. The elevations of high fertility were relatively higher than the other two groups.

Soil resource levels and topographical variation are important for plant diversity and community features. Some aspects of plant community structure, such as composition and diversity of plant functional types, also exert control over plant productivity, sustainability and soil fertility (Tilman et al., 1996).

Table 1 also shows that the coverage, richness, and $\alpha$-diversity index of three layers of plants (tree, shrub and herb) have different features under the three soil fertility levels. The coverage, richness and $\alpha$ diversity index of tree and shrub layers are highest in mid-fertility plots, which have the highest available phosphorus (AP) and potassium (AK) content, but those descriptors of herbs are the lowest. The percentage cover of the herb layer has larger differences in the three fertility levels than for the tree and shrub layers.

Three community groups were distinguished by the tree species characteristics. Twenty-one species existed in all plots of group I and group II, but group III included sixteen species. The dominant species of group I was Quercus liaotungensis, which accounts for $33.5 \%$ of the total species. The second was Maple (16.2\%) and next were Populus davidiana (14.2\%) and Betula chinensis (11.2\%). Group II included Maple (21.7\%), Betula chinensis (21.6\%), Populus davidi- 


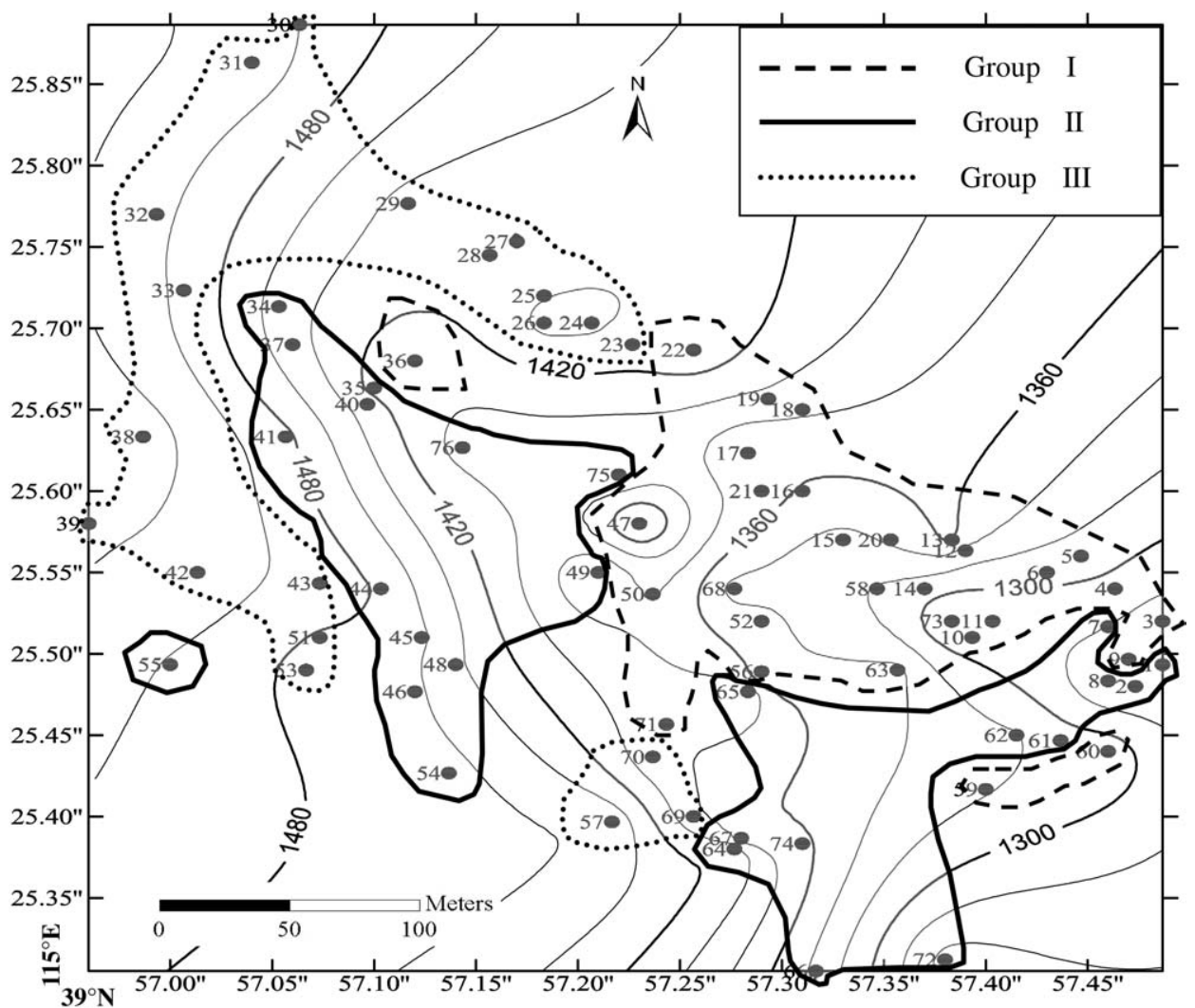

Figure 2. The diagrammatic view of the 76 sampling plots and the sequence numbers of three groups found using cluster analysis (axes represent longitude and latitude).

ana (18.1\%) and Quercus liaotungensis (9.7\%). Group III was Betula chinensis (25.7\%), Populus davidiana (23.2\%) and Quercus liaotungensis (17.6\%).

Diversity in plant communities may be maintained by a variety of mechanisms (Tilman et al., 1996). These include herbivory, site-specific differences in seed dispersal and the differential responses of plants to heterogeneity of resources (including water, nutrients and light).

\section{Canonical Correlation Analysis (CCA)}

The CCA method was used to illustrate the relationships between the three set of factors (soil, topography and plants). Table 2 gives the eigenvalues, proportion, cumulative percentage, and coefficients from canonical correlation. The results indicate that the first canonical correlation of all three pairs was significant at the 0.005 level, which implies a strong relation between the different groups. However, the second canonical correlation did not show significant correlation.
Table 3 presents the standardized canonical coefficients of the canonical correlation analysis. The equations for the topography and plant diversity factors account for $43.7 \%$ of total information, $69 \%$ for topography and soil conditions and $39.6 \%$ for plant diversity and soil features. V1 and $\mathrm{W} 1$ as defined in Table 3 are indices derived from the different factors in the same data set. The coefficient values reflect the degree of influence of each factor. It can be seen from the equations that elevation is a key factor in the landscape and plant diversity groups and has greater effects on the richness of shrubs and plant $\alpha$-diversity index. SOM is influenced mostly by elevation and has a close relationship with shrub coverage. Topographic variability has the largest effect on the most stable pools of soil organic matter (Ingrid et al., 1999). Spatial variability in SOM and TN was highly significant relative to other sources of variability. 
Table 2. Results for the first and second canonical correlation analysis

\begin{tabular}{|c|c|c|c|c|c|c|}
\hline Canonical correlation and canonical variants & & Eigenvalue & Proportion $(\%)$ & Cumulative $(\%)$ & Canonical Correlation & $\operatorname{Pr}>\mathrm{F}$ \\
\hline \multirow[t]{2}{*}{ Topographical and plant factors } & First & 0.517 & $43.7 \%$ & $43.7 \%$ & 0.584 & 0.005 \\
\hline & Second & 0.401 & $33.9 \%$ & $77.7 \%$ & 0.535 & 0.062 \\
\hline \multirow[t]{2}{*}{ Topographical and soil conditions } & First & 0.942 & $69.0 \%$ & $69.0 \%$ & 0.697 & $<0.001$ \\
\hline & Second & 0.239 & $17.5 \%$ & $86.5 \%$ & 0.439 & 0.028 \\
\hline Plant and soil features & First & 0.607 & $39.6 \%$ & $39.6 \%$ & 0.615 & 0.004 \\
\hline
\end{tabular}

Table 3. Standardized canonical coefficients from canonical correlation analysis

\begin{tabular}{ll}
\hline Canonical correlation and canonical variants & Equations of Standardized canonical coefficients \\
\hline Topographical and plant factors & $\mathrm{V} 1=0.78 X_{1}+0.04 X_{2}+0.62 X_{3}+0.41 X_{4}$ \\
& $\mathrm{~W} 1=0.33 Y_{1}+0.43 Y_{2}-0.03 Y_{3}-0.57 Y_{4}-0.90 Y_{5}$ \\
& $-0.03 Y_{6}-0.24 Y_{7}+0.22 Y_{8}-0.31 Y_{9}+0.77 Y_{10}$ \\
Topographical and soil conditions & $\mathrm{V} 1=1.05 X_{1}+0.45 X_{2}+0.08 X_{3}-0.03 X_{4}$ \\
& $\mathrm{~W} 1=0.17 Z_{1}-0.04 Z_{2}+0.98 Z_{3}+0.01 Z_{4}+0.05 Z_{5}-0.02 Z_{6}$ \\
Plant and soil features & $\mathrm{V} 1=0.02 Y_{1}+0.76 Y_{2}-0.51 Y_{3}+0.38 Y_{4}+0.18 Y_{5}$ \\
& $-0.06 Y_{6}+0.51 Y_{7}+0.38 Y_{8}-0.26 Y_{9}+0.09 Y_{10}$ \\
& $\mathrm{~W} 1=0.01 Z_{1}+0.07 Z_{2}-1.10 Z_{3}+1.01 Z_{4}+0.92 Z_{5}+0.12 Z_{6}$ \\
\hline
\end{tabular}

${ }^{*}$ Define $X_{1}=\mathrm{ELE}, \mathrm{X}_{2}=\mathrm{POS}, \mathrm{X}_{3}=\mathrm{ASP}, \mathrm{X}_{4}=\mathrm{GRAD} ; \mathrm{Y}_{1}=\mathrm{COVt}, \mathrm{Y}_{2}=\mathrm{COVs}, \mathrm{Y}_{3}=\mathrm{COVh}, \mathrm{Y} 4=\mathrm{RICHt}$, $\mathrm{Y}_{5}=$ RICHs, $\mathrm{Y}_{6}=$ RICHh, $\mathrm{Y}_{7}=\mathrm{DIVt}_{\mathrm{V}} \mathrm{Y}_{8}=\mathrm{DIV}_{\mathrm{s}}, \mathrm{Y}_{9}=\mathrm{DIVh}, \mathrm{Y}_{10}=\mathrm{DIV} ; \mathrm{Z}_{1}=\mathrm{SW}, \mathrm{Z}_{2}=\mathrm{pH}, \mathrm{Z}_{3}=\mathrm{SOM}$, $\mathrm{Z}_{4}=\mathrm{TN}, \mathrm{Z}_{5}=\mathrm{AP}, \mathrm{Z}_{6}=\mathrm{AK}$. $\mathrm{V} 1$ and $\mathrm{W} 1$ as defined are indices derived from the different factors in the same groups.

\section{Conclusions}

Most of the early studies were conducted in ecosystems dominated by shrubs or grasses rather than forests. In this study the interrelationship and relative roles of plant diversity and topography have been investigated to determine the effect to which they influence soil properties in a small watershed in Donglingshan Mountains near Beijing. Seventy six plots were studied, and detailed plant diversity, topography and soil features were recorded. The study area is also characterized by complex topography and heterogeneous vegetation.

Multivariate statistical analysis techniques were used to establish the relationships between plant diversity, topography and soil factors. Plant community structure and biodiversity have been shown to have a high degree of spatial variability that is controlled by both abiotic and biotic factors. Results from PCA and CA indicate that plant diversity and topography conditions should be considered in explaining variability in soil properties. Organic matter is a critical factor for soil fertility and three fertility levels are distinguished by SOM content. Many studies in semiarid and arid regions have shown a significant topographic influence on accumulation of soil organic matter (Burke et al., 1997). Our analysis showed that topography explained much variance in SOM. High fertility level plots often exist on the upper and gentler slopes while the lower and steeper slope had greater disturbance and soil erosion in the research area. The coverage, richness, and $\alpha$-diversity index of tree and shrub layers are the highest in mid-fertility plots, which had the highest available phosphorus (AP) and potassium (AK) contents, but the herb layer exhibited the lowest values. CCA was used because of the large number of variables involved in this study. The analysis elucidated the relationships of three different index groups (topography, soil and plant). Elevation and aspect have close relationships with shrub richness and the $\alpha$ diversity index. Elevation has a positive relationship with soil organic matter (SOM). SOM and total nitrogen in the soil factor group have the greatest effects on plant characteristics, mainly on shrub coverage. The results confirmed that topographic variability had great effect on the most stable pools of soil organic matter. 


\section{Acknowledgements}

We thank the members of our team from Beijing Forestry University and Northwest Sci-Tech University of Agriculture and Forestry for their help with vegetation and soil sampling. The project was supported by the Chinese Academy of Science (No. KZCX2405) and National Natural Science Foundation of China (No. 30070141). Gratitude is expressed to the reviewers for their valuable suggestions in improving the manuscript.

\section{References}

Aguiar M R and Sala O E 1999 Patch structure, dynamics, and implications for the functioning of arid ecosystems. Trees 14, 273-277.

Aguilar R. and Heil R D 1988 Soil organic carbon, nitrogen and phosphorus quantities in Northern Great Plains rangeland. Soil Sci. Soc. Am. J. 52, 1076-1081.

An S Q, Wang Z F, Liu Z L, Hong B G and Zhao R L 1997 Effects of soil factors on species diversity in secondary forest communities. Acta Ecologica Sinica 17(1), 45-50 (in Chinese with English abstract).

Burke I C, Lauenroth W K, Parton W J 1997 Regional and temporal variation in net primary production and nitrogen mineralization in grasslands. Ecology 78, 1330-1340.

Chen L Z 1997 The importance of Donglingshan mountain region in warm temperate zone deciduous broad-leafed forests. In Study on the structure and function of forest ecosystem in warm temperate zone. Eds. L Z Chen. pp. 1-9. Chinese Science Press, Beijing, China (in Chinese).

Editorial Committee 1996 Soil physical and chemical analysis and description of soil profiles. Standards Press of China, Beijing, China. 120 pp. (In Chinese).

FAO-UNESCO 1988 Soil Map of the World, Revised Legend. World Soil Resources Report 60 Rome.

Fu B J, Chen L D, Ma K M Zhou H F and Wang J 2000 The relationships between land use and soil conditions in the hilly area of the loess plateau in northern Shaanxi, China. Catena 39, 69-78.

Hong $\mathrm{N}$ and Hou J 2001. Tutorial of SAS for Windows, Publishing house of electronics industry, Beijing, $252 \mathrm{pp}$. (in Chinese).

Ingrid C B, William K L, Rebecca R, Peter B, Brian M and Scott B 1999 Spatial variability of soil properties in the shortgrass steppe: The relative importance of topography, grazing, microsite, and plant species in controlling spatial patterns. Ecosystems 2, 422438

Jackson R B and Caldwell M M 1993 Geostatistical patterns of soil heterogeneity around individual perennial plants. J. Ecol. 81, 683-692.
Liu C. M. Li C. Z. Shi M. H. and Liang H. Y. 1996. Multivariate statistical analysis techniques applicated in differentiation of soil fertility. Acta Ecologica Sinica 16, 444-447 (in Chinese with English abstract).

Ludwig J A and Tongway D J 1995 Spatial organization of landscapes and its function in semi-arid woodlands, Australia. Landscape Ecol. 10, 51-63.

Ma K M, Fu B J, Guo X D and Zhou H F 2000 Finding spatial regularity in mosaic landscapes: Two methods integrated. Plant Ecol. 149, 195-205.

McBratney A B and Webster R 1981 Spatial dependence and classification of soil along a transect in north-east Scotland. Geoderma 26, 63-82.

Michael L C, Scott S, Jonathan P E and Marie J F 1999 Sampling spatial and temporal variation in soil nitrogen availability. Oecologia 118, 397-404.

Nelson D W and Sommers L E 1975 A rapid and accurate method for estimating organic carbon in soil. Proc. Indiana Acad. Sci. 84, 456-462.

Odeh I O A, Chittleborough D J and McBratney A B 1991 Elucidation of soil-landform interrelationships by canonical oridination analysis. Geoderma 49, 1-32.

Pickett S T A and Cadenasso M L 1995 Landscape ecology: Spatial heterogeneity in ecological systems. Science 269, 331-334.

Schimel D S, Coleman D C and Horton K A 1985a Soil organic matter dynamics in paired rangeland and cropland toposequences in North Dakota. Geoderma 36, 201-214.

Schimel D S, Stillwell M A and Woodmansee R G 1985b Biogeochemistry of $\mathrm{C}, \mathrm{N}$, and $\mathrm{P}$ in a soil catena of the shortgrass steppe. Ecology 66, 276-282.

Su J M, Fu R H, Zhou J B and Zhang L H 2000 Practical guide of SPSS 10.0 for Windows. Publishing house of electronics industry, Beijing, China. 287 pp. (in Chinese).

Tilman D, Wedin D and Knops J 1996 Productivity and sustainability influenced by biodiversity in grassland ecosystems. Nature 379, 718-720.

Vinton M A and Burke I C 1995 Interactions between individual plant species and soil nutrient status in shortgrass steppe. Ecology 76, 1116-1133.

Vinton M A and Burke I C 1997 Plant effects on soil nutrient dynamics along a precipitation gradient in Great Plains grasslands. Oecologia 110, 393-402.

Watt A S 1947 Pattern and process in the plant community. J. Ecol. $35,1-22$.

Wedin D A and Tilman D 1996 Influence of nitrogen loading and species composition on the carbon balance of grasslands. Science 274, 1720-1723.

Yonker C M, Schimel D S, Paroussis E and Heil R D 1988 Patterns of organic carbon accumulation in a semiarid shortgrass steppe, Colorado. Soil Sci. Soc. Am. J. 52, 478-483.

Zhang J and Oxley R R B 1994 A comparison of three methods of multivariate analysis of upland grasslands in North Wales. J. Veg. Sci. 5, 71-76. 